\title{
Retos en el cáncer oral
}

\author{
Challenges of the oral cancer
}

El diagnóstico precoz del cáncer oral es un objetivo prioritario de salud, en el que los profesionales de la salud oral pueden jugar un papel fundamental. La detección debe conducir a menos daño que la terapia del cáncer y esto es esencial para un mejor pronóstico. Aproximadamente del 5\% al 15\% de la población general puede tener una lesión en la mucosa oral, aunque la mayoría son benignas, el examen clínico por sí solo no puede diferenciar qué lesiones son potencialmente precancerosas y cancerosas y cuáles son benignas (1). La presentación clínica clásica de una lesión premaligna o maligna incluye una placa blanca, una placa roja o una úlcera que no cura o cicatriza. Sin embargo, sólo un pequeño porcentaje son malignas; y un examen oral lamentablemente no puede discriminar entre lesiones que son potencialmente malignas, de las benignas.

Actualmente, existe un número de técnicas novedosas que pueden ayudar de diversas formas en el diagnóstico de malignidad oral. Así, los sistemas de detección basados en luz han sido presentados para mejorar la sensibilidad y especificidad, pero hasta el momento, los estudios controlados no han podido justificar completamente esto. La biopsia es el método diagnóstico para evaluar las lesiones orales sospechosas que pueden ser precancerosas o cancerosas. Los sistemas basados en luz sólo deben ser empleados como un complemento al examen clínico, para la identificación de lesiones orales que pueden haber sido pasadas por alto con un examen oral convencional y no para la determinación de la naturaleza biológica de una lesión. Sin embargo, se requieren ensayos controlados en poblaciones de alto y bajo riesgo con resultados histológicos y valoración crítica, antes que puedan integrarse a la práctica (1).

Se sabe que el pronóstico para los pacientes con carcinoma de células escamosas de cavidad oral (CCE) sigue siendo pobre a pesar de los avances en el tratamiento de esta neoplasia maligna. Fundamentalmente, el diagnóstico y tratamiento temprano siguen siendo la clave para mejorar la supervivencia de los pacientes. Pero, para el diagnóstico es indispensable la biopsia con bisturí, lamentablemente es un método invasivo y tiene el potencial de morbilidad. Además, tiene una variabilidad interobservador e intraobservador en el diagnóstico histológico de displasia epitelial. Entonces, hay la necesidad de idear herramientas de diagnóstico críticas para la detección precoz de la displasia oral y malignidad, que sean: prácticas, no invasivas, y se puedan realizar fácilmente en una consulta ambulatoria. Los exámenes de diagnóstico para la detección temprana incluyen la biopsia por cepillo, la tinción de azul de toluidina, autofluorescencia, proteómica salivales, el análisis de ADN, los biomarcadores y la espectroscopia (1).

En los últimos años existe un creciente interés en el diagnóstico basado en el análisis de la saliva dado que su colección es simple y no invasiva. Estas características hacen que sea posible supervisar diversos biomarcadores en saliva de bebés, niños, adultos mayores y sujetos no colaboradores, y en circunstancias en la cual la sangre y 
orina de muestreo no están disponibles. El estado de la técnica proteómica salival esta en evolución progresiva y un número creciente de aplicaciones clínicas se han establecido para vigilar las condiciones y enfermedades locales y sistémicas. El campo de investigación más importante de la proteómica salival es la oncología (cancerogénesis). Sin embargo, algunos resultados obtenidos son a veces contradictorios, por lo que se requieren mayores estudios (2).

El descubrimiento que las células tumorales heterogéneas del CCE de cabeza y cuello exhiben un espectro de potenciales tumorigénicos, nos ha motivado significativamente para la aplicación de la biología, particularmente las células madre en la patogenia de esta neoplasia, aunque queda mucho trabajo por hacer. Por ejemplo, si existen células madre cancerosas como en las lesiones premalignas y cuál es su comportamiento y función a través del proceso de múltiples pasos de progresión de la enfermedad no está claro. Sin embargo, lo que sí está claro, es que el desarrollo de terapias basadas en mecanismos para controlar el cáncer oral requerirá comprensión más profunda de los procesos biológicos que en generar las células que conducen a recurrencia y diseminación metastásica. Las células madre del cáncer de cabeza y cuello residen principalmente en nichos perivasculares en el frente invasivo donde los acontecimientos iniciados en células endoteliales contribuyen a su supervivencia y función (3).

Las células madre del cáncer se encuentran en los frentes invasivos del CCE cerca de los vasos sanguíneos (nicho perivascular). La señalización celular iniciada por eventos endoteliales es fundamental para la supervivencia y auto-renovación de estas células madre. Marcadores tales como aldehído deshidrogenasa (ALDH), CD133, y CD44 se han utilizado con éxito para identificar las células madre del cáncer altamente oncogénico en esta neoplasia. La evidencia reciente sugiere que las células madre del cáncer son exquisitamente resistentes a la terapia convencional y son los "drivers" de recidiva local y la diseminación metastásica. Los CCE pueden tener un profundo impacto en los paradigmas de tratamiento para esta malignidad (4).

Muchas de las células del cáncer contienen una subpoblación de células madre de autorrenovación conocidas como células madre del cáncer. A diferencia de las células madre adultas normales que permanecen constantes en número, éstas pueden aumentar en número como tumores, crecer, y dar lugar a una progenie que puede ser localmente invasivas y colonizar lugares distantes (características de la malignidad) (5). Es tentador especular que la combinación de terapias dirigidas a la reducción de volumen del tumor (por ejemplo, cirugía, quimioterapia, radioterapia convencional) junto con terapias específicas dirigidas a la eliminación de las células madre del cáncer podrían tener un impacto positivo en el resultado a largo plazo de los pacientes con cáncer oral en el futuro (3). En consecuencia, la aplicación de las técnicas de biología molecular en la investigación biomédica han sido muchas y de gran aplicación clínica, todo esto nos da los fundamentos necesarios para nuestra práctica clínica de hoy y del futuro, en beneficio de la población.

Sonia Sacsaquispe-Contreras ${ }^{1, a, b, c, d}$

\section{REFERENCIAS BIBLIOGRÁFICAS}

1. Mehrota R, Gupta DK. Exciting new advance in oral cancer diagnosis: avenues to early detection. Head \& Neck Oncology. 2011; 3(33):1-8.

2. Castagnola M, Picciotti PM, Messana I, Fanali C, Fiorita A, et al. Potencial applications of human saliva as diagnostic fluid. Acta Otorhinolaryngol Ital. 2011;
31(6):347-57.

3. Zhang Z, Sant M, Nör JE. The biology of head and neck cancer stem cells. Oral Ondol. 2012; 48(1):1-9.

4. Krishnamurthy S, Nör JE. Head and Neck Cancer Stem Cells. J Dent Res. 2012; 91(4):334-40.

5. Alison MR, Islam S. Wright NA. Stem cells in cancer: instigators and propagators? J Cell Science. 2010; 123(14):2357-68.

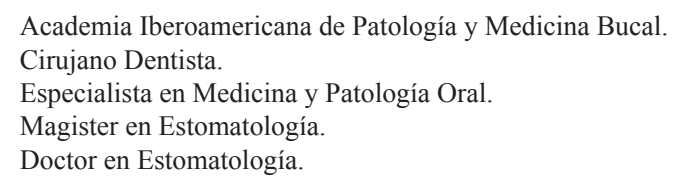

